\title{
SPIN STRUCTURES OF Fe/Gd and Fe/Cr MULTILAYERS \\ DETERMINED BY POLARIZED NEUTRON REFLECTOMETRY
}

M. Loewenhaupt and W. Hahn

ANL/CP -77178

Institut für Festkörperforschung

Forschungszentrum Jïlich

DE93 000510

Y. Y. Huang and G. P. Felcher

Materials Science Division

Argonne National Laboratory

Argonne, IL 60439

S. S. P. Parkin

IBM Almaden Research Center

San Jose, CA

The submitted manuscript has been authored by a
contractor of the U.S. Government under contract No.
W-31-109-ENG-38. Accordingly, the U.S. Government
retains a nonexclusive, royalty-Iree Ucense to publish
or reproduce the published form of this contribution, or
allow others to do so, for U.S. Government purposes.

August, 1992

$/ \mathrm{sm}$

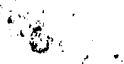

Proceedings to be published from the Symposium on Magnetic Ultra Thin Films

Multilayers and Surfaces, Lyon, France, September 7-10, 1992

This work was performed under the of the U. S. Department of Energy, Division of Basic Energy Sciences, Materials Sciences, Contract No. W31-109-ENG-38.

\section{DISCLAIMER}

This report was prepared as an account of work sponsored by an agency of the United States Government. Neither the United States Government nor any agency thereof, nor any of their employees, makes any warranty, express or implied, or assumes any legal liability or responsibility for the accuracy, completeness, or usefulness of any information, apparatus, product, or process disclosed, or represents that its use would not infringe privately owned rights. Reference herein to any specific commercial product, process, or service by trade name, trademark, manufacturer, or otherwise does not necessarily constitute or imply its endorsement, recommendation, or favoring by the United States Government or any agency thereof. The views and opinions of authors expressed herein do not necessarily state or reflect those of the United States Government or any agency thereof. 


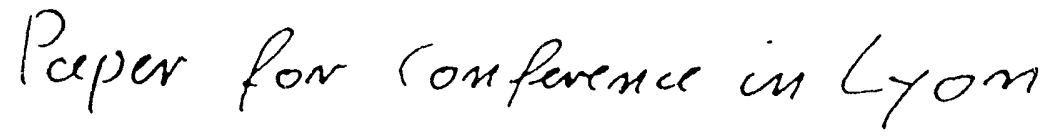

$1 / 6$

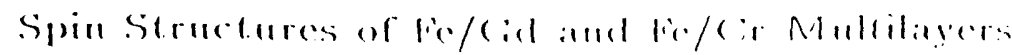

Determined by Polarized Nentom Rellectometry

M. Locewenhanpi and W. Hahlu

Institut für fesckörperforschung, forschungs\%entrum dülich,

Postfach 1913, D) 5170 Jülich Germany

Y.Y. Huang and G.P'. Felcher

Material Science Division, Argonne Nal. Lab., Argonnc II, 60439-1845 USA

and

S.S.P. Parkin

IBM Almaden Research Center, San Jose CA 95120-6099 USA

Keywords: $\mathrm{Fe} / \mathrm{Gd}$ multilayers; $\mathrm{Fe} / \mathrm{Cr}$ multilayers; polarized neutron reflectometry.

Running title: Spin Structures of Fe/Gd and Fe/Cr Multilayers.

Author to whom correspondence should be addressed:

M. Locwenhaupt

IFP/KFA Jülich

Postrach 1913

D) - 5170 Jïlich, Germany
'Lel: $49-2461-613139$

lisX: $19-2461-612610$

E-M ail: HFO87@IJUKFA11 


\begin{abstract}
Alsitialct

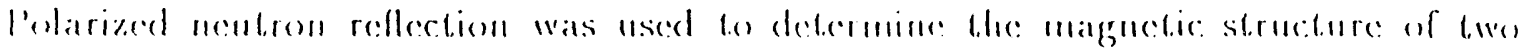

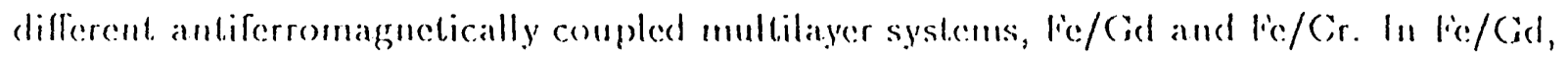
the Fe and Gd moments are compled antiparallel at the interface. Al low temperatures a surface induced magnetic phasc transition was found. In lic/ $\mathrm{Cr}$, annealing al tcmperatures of up to $425^{\circ} \mathrm{C}$, resulted in the degrading of antiferromagnetic coupling between fic layers and in the formation of ferromagnetically coupled regions.
\end{abstract}




\section{Introduction}

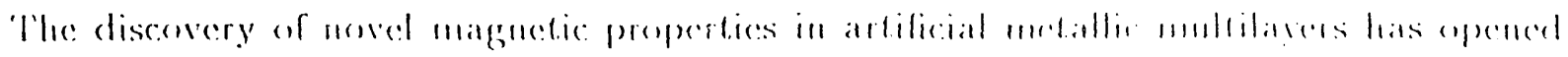
an entirely new field of investigations [1]-[3]. In these materials the individual hayers, a

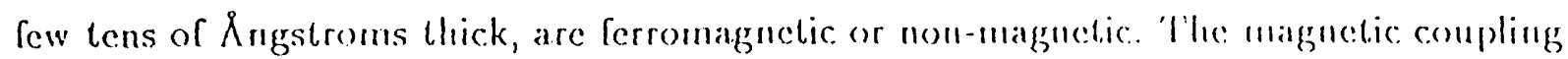
between layers can be varied, giving rise to parallel (li) or anliparallel (Ali) magnetic configurations, by changing layer thickness, chemistry, or magnelic fick. Questions have arisen about the lrue parallelism (or antiparallelism) of the magnctization of different layers; the stability and the uniformity of the magnelic coordinalion; the correlation between magnetic and chemical structure. A useful tool in investigating such properties is polarized neutron diffraction (PNR). However the thickness of the layers is such that the first Bragg reflection occurs at very small angle, close to the incident bearn and also close to the region of total reflection. We would like to give in this paper lwo examples of the application of of "stretched" polarized neutron reflectometry, or of diffraction at very small angle $[4,5]$.

The specular reflectivity is a function of wavevector transfer q perpendicular to the surface yielding pallerns whose basic fealures can be described by a simple rule. Since $q$ is a coordinate in reciprocal space, to proceed from the region of small cy onward means to pass from a coarse-grained to a more detailed vision of the chemical and magnetic profite of the film. Unfortunately this can be done only at the cost of intensity, since the reflectivity decreases $\left[\right.$ (6) as $q^{-1}$. When g reaches a value corresponding to the superlathice spacing the prominent feature of the reflectivity profite is the comset of the lirst Braggr dilfraction peak.

The neutron measurements were taken with the polarized neutron reflectometer POSY I 


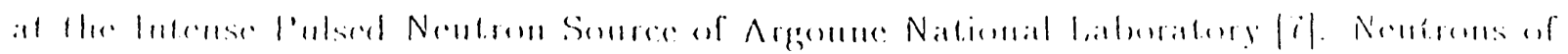

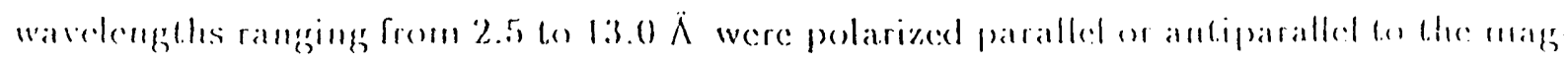

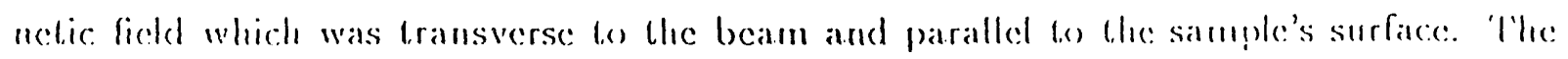
spin--dependent reflectivitics $\left(R^{+}, R^{-}\right)$were measured in a position-scusilive delecelor at. an angle 20 with the primary beam. Practically speaking, this instrument operalcs like a. $0-2 \theta$ diffractometer but with very high resolution $\left(\mathrm{dq}=0.0004 \AA^{-1}\right)$ and limiled range $\left(0.001 \AA^{-1}<q<0.120 \AA^{-1}\right)$

\section{$2 \mathrm{Fe} / \mathrm{Gd}$ multilayers}

$\mathrm{Fe} / \mathrm{Gd}$ multilayers exibit a strong interface antiferromagnetic coupling between $\mathrm{Fe}$ and Gd. The Fe and Gd layers themselves are simple ferromagnets with vastly different Curie temperatures and relatively weak anisotropy. For an idealized system of this kind Camley' and co-workers $[8,9]$ suggested an interesting magnetic phase diagram. In this model the ferromagnetic Gd-Gd interaction is much weaker than the ferromagnetic FeFe interaction or the antiferromagnetic one at the contact of the two matcrials. Thus, as the temperature is raised, the ordered moment of Gd (larger than Fe in the ground state) decreases faster than that of Fe. In the ground state the system is Gd-aligned. Raising the temperature the system becomes compensated, and then fie-aligned. 'The onset of an external magnetic ficld creales additional phases. In weak magnetic fields the aligned state persists, and the magnelizalion remains constant. Ne a critical field a new structure, called "wisted", appears [9]. In hiss structure only lhe (id and fe components perpendicular to the lield are coiapensating cach other.

The field induced transition from the Gd aligned the the twisted state is decply per- 


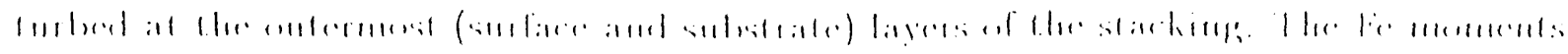

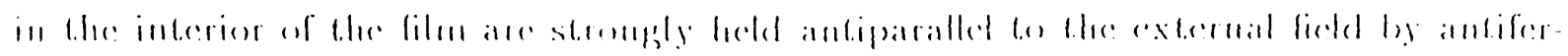

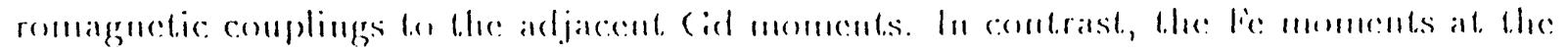

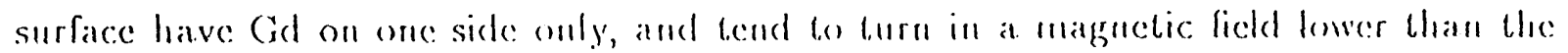
critical ficld for the bulk transition. If the multilayer is terminated with Gid, the opposite eflect lakes place: the twisting starts in the interior while lwisting near the surface requires a much higher field because it is hindered by the prescrice of Gid at the surface. These qualitative arguments have been backed up by rigorous calculations [8]. "'he phase diagrams and the corresponding spin struclures are shown schernatically in fig. 1. Magnelization [10,11] and Mössbauer [12] measurements on evaporated Gd/Fe mullilayers indicaled the presence of a phase transition similar to that predicted by Camley. However these techniques were not able to detect the twisted state al the surface. We therefore attempted to inspect il more directly by PNR.

The samples we investigated were oblained by alternately depositing Fe and Gd layers on 1" Si(111) wafers in a high-vacuum dc magnetron spullering system. Each sample comprised a buffer layer of $56 \AA \mathrm{Cr}$, followed by a tolal of 15 ( $\mathrm{Fe} 35 \AA / \mathrm{Gd} 50 \AA$ ) bilayers and protected by another layer of $56 \AA \mathrm{Cr}$ to prevent oxidation of the more reactive lie and Gd. Two samples were prepared: one with Fe facing the surface, and Gd the substrate the second with Gd facing the surface, and Fe the substratc. We prescul here the results obtained at $15 \mathrm{~K}$, well below the compensalion temperature of $130 \mathrm{~K}$.

figg. 2 shows the spin dependent reflectivities of the sample with fie al the surface when magrolic fields $11=3800$ ond $1 \mathrm{kO}$ () are applied. 'The reflectivity curves on the left side are obtained with neutrons entering from the front side, and the curves on the right side with neutrons entering on the back side, throngh the silicon substrate. In low 


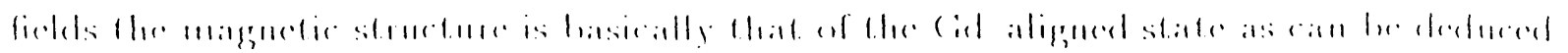

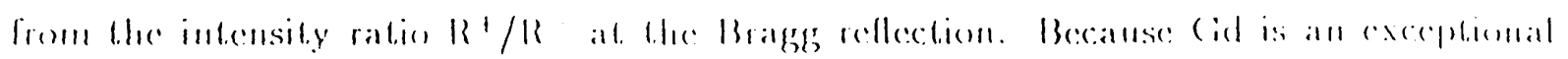
strong nentron absorber the measured rellectivity curves are surface sensitive. The spin dependence of the reflectivity of the fromt. face: (lie outermost hayer) changes with field much more dramalically than that of the back face (Gd outcrmost layer). 'The opposite is observed for the second, or complementary sample (not shown here). These ubservations give evidence that the field induced magnetic phase transilion from a Gd-aligned to a twisted state starts at the Fe-terminated surface and is hindered at the Gd-terminated surface. This is in accordance wilh the predictions of Camley. To go further, and fully confirm the applicability of Camley's model a quantilative analysis of the results is necded. This and an extensive study of the spin-analyzed reflectivity are now in progress, and should enable us to verify not only the existence, but the detailed structure of the surface twisted state.

\section{$3 \quad \mathrm{Fe} / \mathrm{Cr}$ Multilayers}

This is the prototype and the most studied of all AF/F multilayers [1]-[3] coupled through intermediate layers. It is well known that in sputtered samples, the iron layers (typical thickness: $20 \AA$ ) are $\Lambda F$ coupled across Cr layers up to $15 \AA$ thick; llicn llicy are $F$ coupled until Cr is $22 \AA$ thick, and so on. Higher frequency $\wedge \mathrm{F} / \mathrm{F}$ oscillations appear [13] for epitaxially deposited samples. Af fe/Cr multilayers show a giant magnetoresistance; it.s value is strongly dependent on the way the sample is prepared $[2,3]$. Whe wemlel like: here to show the effect of annealing on the magnetoresistance and the concurrent dianges in the magnetic configuration as revealed by l'NR. 


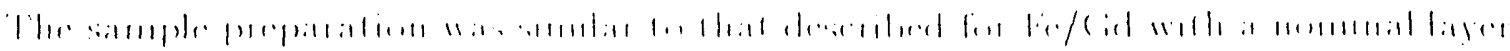

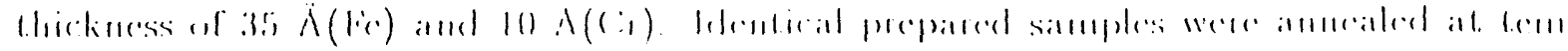

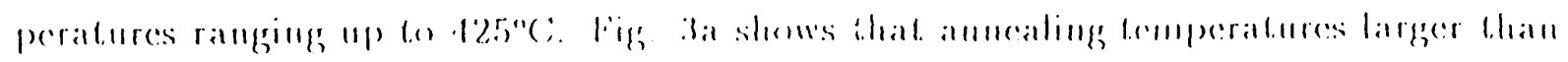

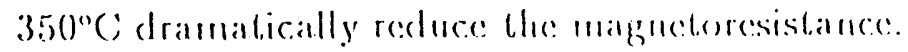

Fig. 1 shows the ficld edependent diffraction patterns of a sample annealed at 350 "C:

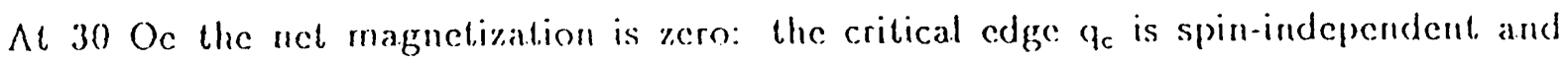
so is the first structural Bragg reflection, at $q=0.16 \AA^{-1}$. The magnelization of the sequential Fe layers is arranged as in the +-+- sequence, giving risc to the $\Lambda \mathrm{E}$ peak al $q=0.08 \AA^{-1}$, which is spin-independent. $\Lambda \mathrm{t} 4 \mathrm{kOc}$ a ferromagnetic component is present: this is made evident by the large spin dependence at $q_{c}$ and at the Bragg peak. On the other hand, the intensity of the AF peak, which is always spin-independent, is severely diminished. Figs. $3 b$ and $3 c$ give the sublattice $(A F)$ and net $(F)$ magnetization for all samples as a function of the applied magnetic field as deduced from the reflectivity curves.

Let us try to interpret the results of fig. 3 in terms of a simple model. Assume that the AF component of the Fe moments lies in the film plane and perpendicular to the magnetic field: this is the spin flop state. Assume also that the F component is aligned with the applied magnetic field. 'The total mornent per le atom remairis approximately constant for fields larger than $1 \mathrm{kOc}$, and is similar to the moment of fe in bulk iron. However for weaker magnetic fields this empirical rule docs not hold entirely, and actually the $\triangle P$ contribution is secn to increase with field. In this region not all antiferromagnetic domains

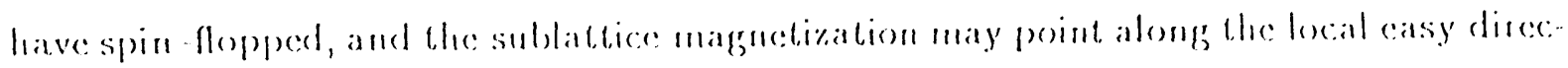
tion. Ae these fields it is observed that the $\wedge F$ peak is broad and that the meutrons are partially reflected, partially scattered at 20 angles above and below the reflected line, as if the AF domains were laterally limited [11]. Pxperimentally, the scaltered radiation was 


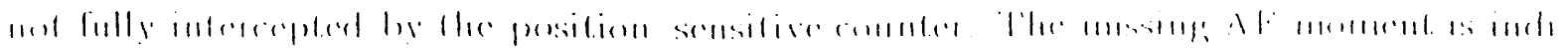

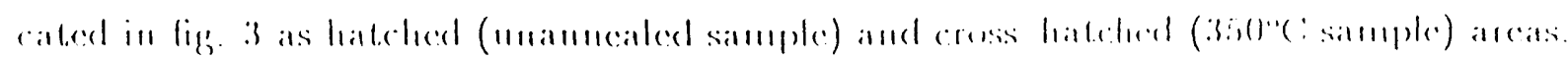

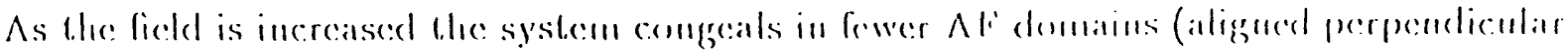
to the magnelic fiedd) and the sharpened AF peak is fully acceptect hy the commter.

'The presence of both find $\Lambda F$ components in a reflection spectrum can be interpreted in two ways. In an applied magnetic field, lhe magnctioalion of cach layer can be canted with an $\Lambda F$ component perpendicular to the applied field and a $F$ component in field direction. In this picture the magnetic structure is uniform throughout the sample. In an alternate picture the sample is intomogeneous, and composed of separate $F$ and $A F$ regions. Both cases give the sarne diffraction pattern. However, it can be noticed that while for the virgin sample $F$ and $A F$ components are present only in sireable magnetic fields, for annealed samples a substantial ferromagnetic moment is present even in very weak fields. We can understand the development of $F$ regions as resulting from the dissolution of the interfaces at annealing temperalures above $350^{\circ} \mathrm{C}$. There are at least two possible ways to produce $\mathrm{F}$ coupling: (i) direct coupling from Fe bridges across the Cr layers and (ii) indirect coupling changing from $\Lambda \mathrm{F}$ to $\mathrm{F}$ for decreasing thickness of the dissolving Cr spacer layer.

\section{Acknowledgements}

Work at $\Lambda$ rgonne was supported by the U.S. Department of Energy, Basic Bncrgy' Sciences, Material Sciences, moder contract No. W-31-109-ENG-38 


\section{Reforencess}

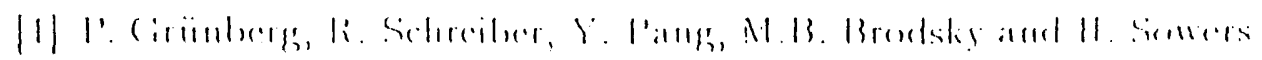
I'luss. Re:n. Le:11. 57 (1988(i) 2412.

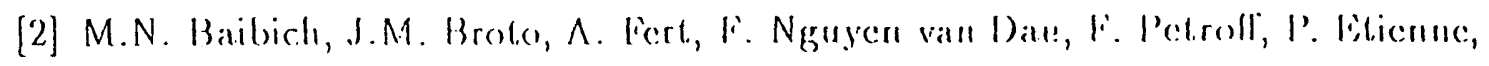
G. Creuzct and $\Lambda$. liricderich, l'hys. Rev. Lell. 61 (1988) 2172.

[3] S.S.P. Parkin, N. More and K.P. Roche, P'hy. Rev. Lell. 64 (1990) 2304.

[4] S.S.P. Parkin, A. Mansour and G.P. Felcher, Appl. Phys. Lell. 58 (IS91) 1473

[5] C.F. Majkrzak and G.P. Felcher, Mal. Res. Soc. Bullelin (Nov.1990) p. 65-72

[6] J. Lekner in Theory of Reflection, (Malinus Nijioff Publisher, Dordrecht 1987)

[7] G.P. Felcher, R.O. Hilleke, R.K. Crawford, J. Haumann, R. Kleb and G. Ostrowski Rev. Sci. Instrum. 58 (1987) 609.

[8] J.G. LePage and R.E. Camley, Phys. Rev. Lelt. 65 (1990) 1152.

[9] R.E Camley and D.R. Tilley, Phys. Rev. B37 (1988) 3413.

[10] II. Fujimori, Y. Kamiguchi and Y. Hayakawa, I. Appl. Phhss. 67 (1990) 5716.

[11] K. Cherif, C. Dufour, Ph. Baucr, G. Marchal and Ph. Mangin Phys. Rev. B44 (1991) 7733 .

[12] Ph. Bauce, M. Sajieddine, C. Dufour, K. Cherifi, G. Marchal and Ph. Mangin likrophys. Lell. 16 (1991) 307.

[13] J. Unguris, R... Cecotta and D.'T. Pierec, I'tys. Rev. Letl. 67 (1991) 140.

[14] Y.Y. Huang, G.P. Felcher and S.S.P. Parkin, J. Magn. Magn. Mal. 99 (1991) 1.31. 


\section{Fignere (ial)tions}

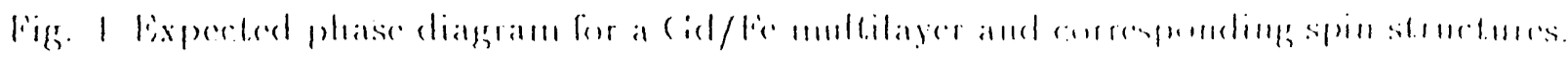

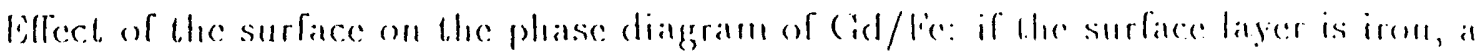
twisted state is induced at the surface in a fickd musch lower than for lhe bulk. In contrast, Gd at the surface hinders the transition. Not shown are the disordered phase (high temperalure) and the ficld-aligned phase (high magnelic ficld).

Fig. 2 Spin-dependent reflectivities of the $[\mathrm{Ec} 35 \AA / \mathrm{Gd} 50 \AA] \times 15$ sample with lic at the surface and $\mathrm{Gd}$ facing the substrate measured at $\mathrm{T}=15 \mathrm{~K}$ from iront (pictures on the left) and backside (pictures on the right). Full circles: $\mathrm{R}^{+}$, open circles: $\mathrm{R}^{-}$.

Fig. 3 Magnetoresistance, antiferromagnetic $(\Lambda F)$ and ferromagnetic (F) moment components of the magnetization of sputtered $[\mathrm{Fe} 30 \AA / \mathrm{Cr} 10 \AA] \times 30$ multilayers, in the virgin and annealed states. Hatched and cross-hatched areas indicate missing AF moment of unannealed and $350^{\circ} \mathrm{C}$ sample, respectively.

Fig. 4 Spin-dependent reflectivities of a $[\mathrm{Fe} 30 \AA / \mathrm{Cr} 10 \AA] \times 30$ multilayer annealed at $350^{\circ} \mathrm{C}$. Full cirles: $R^{+}$, open circles: $R^{-}$. 


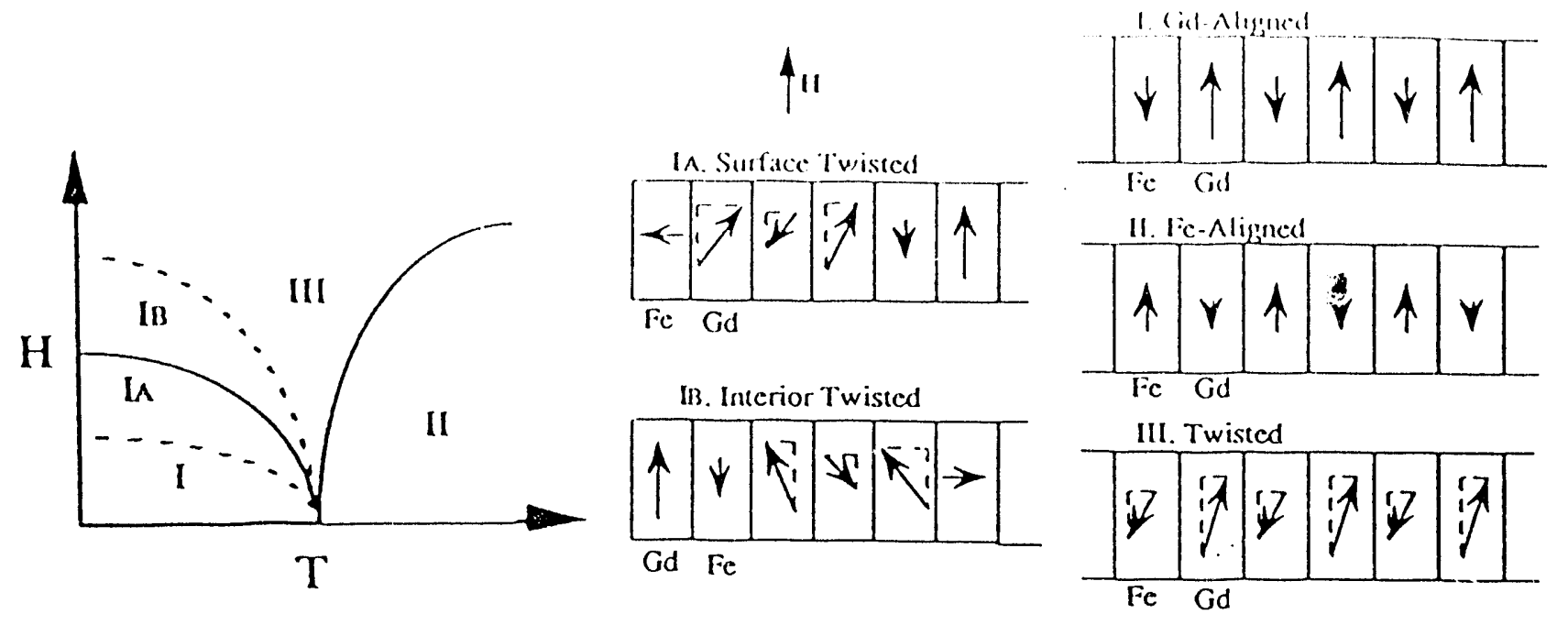

Fiy:1 

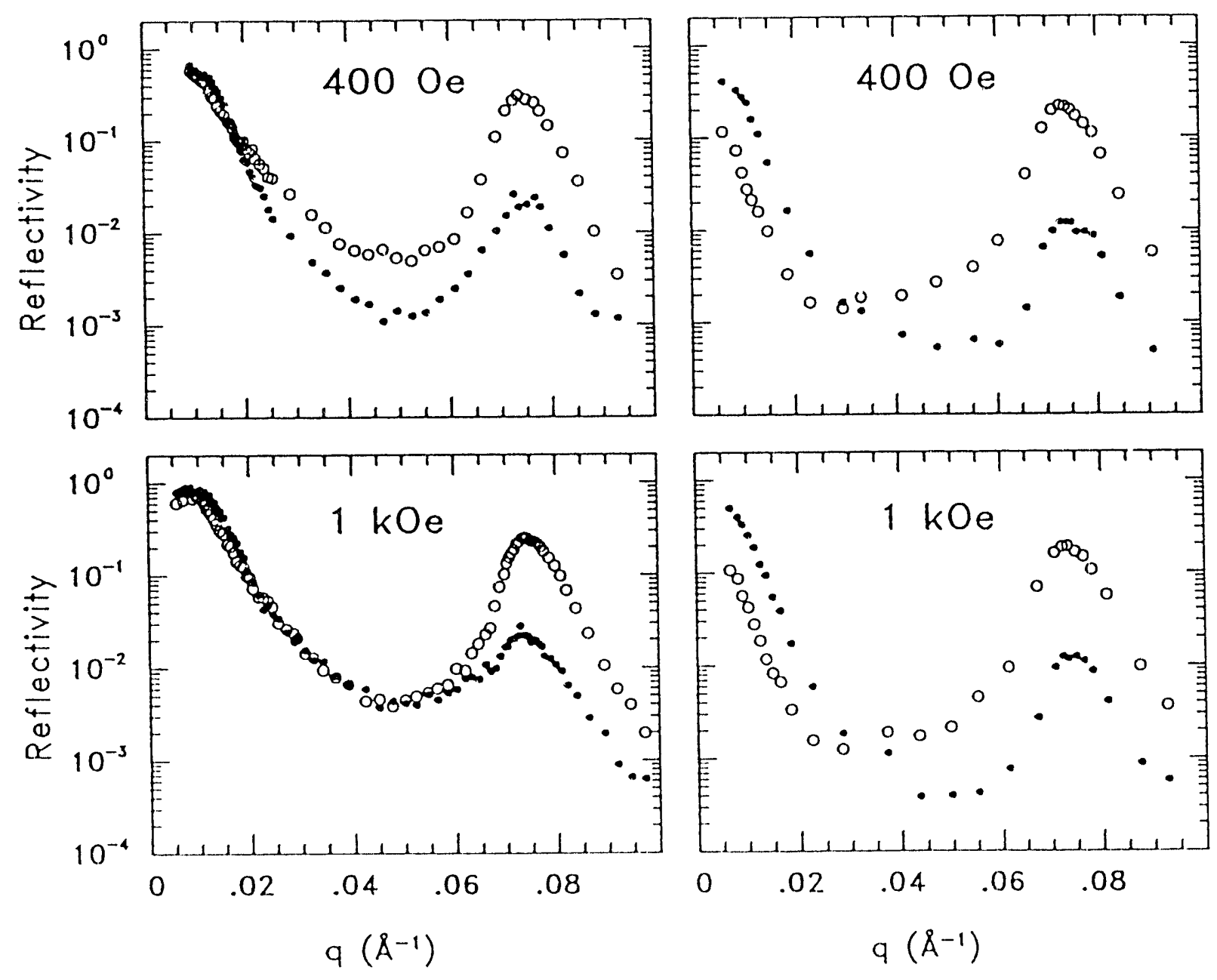

Fig 2 

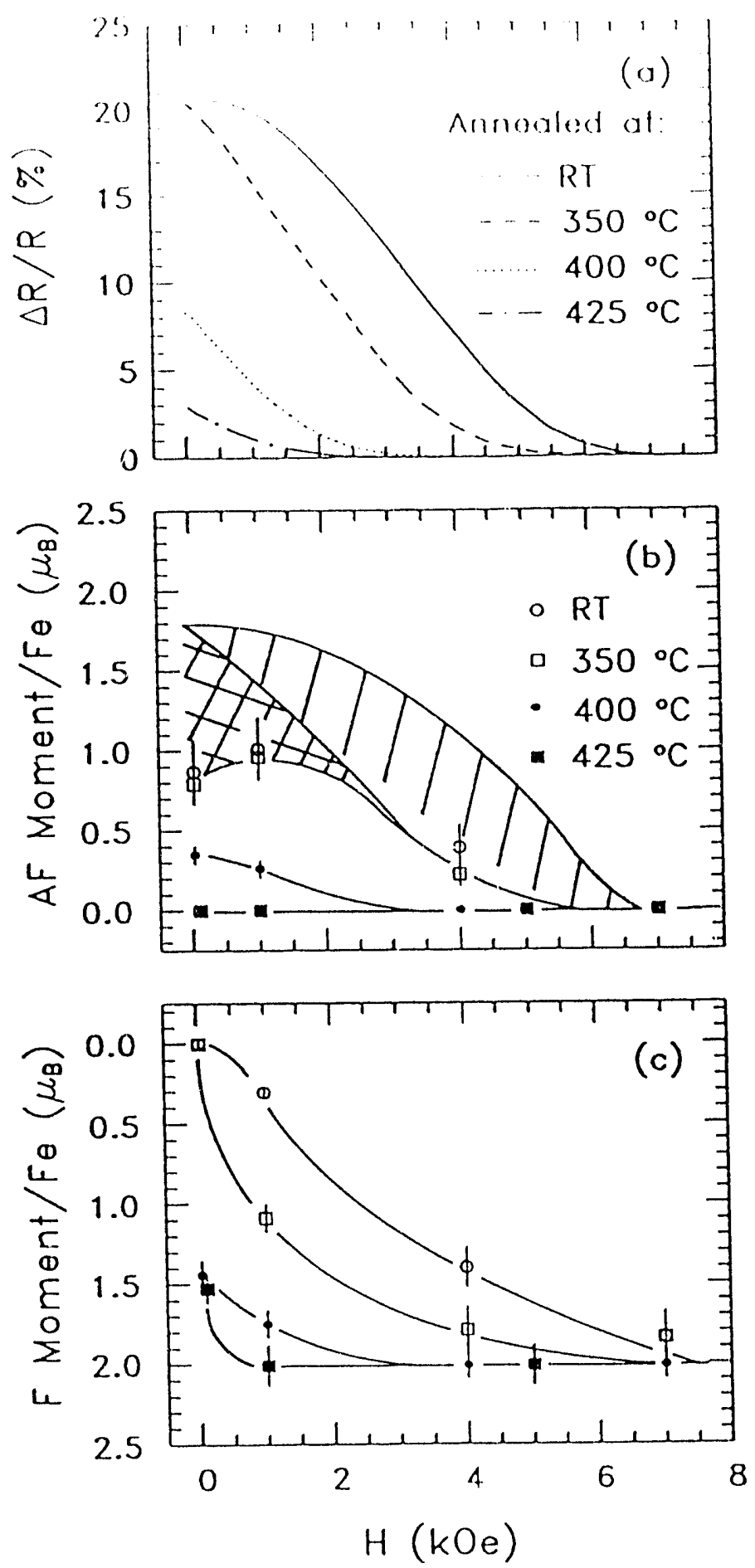

Fig 3 

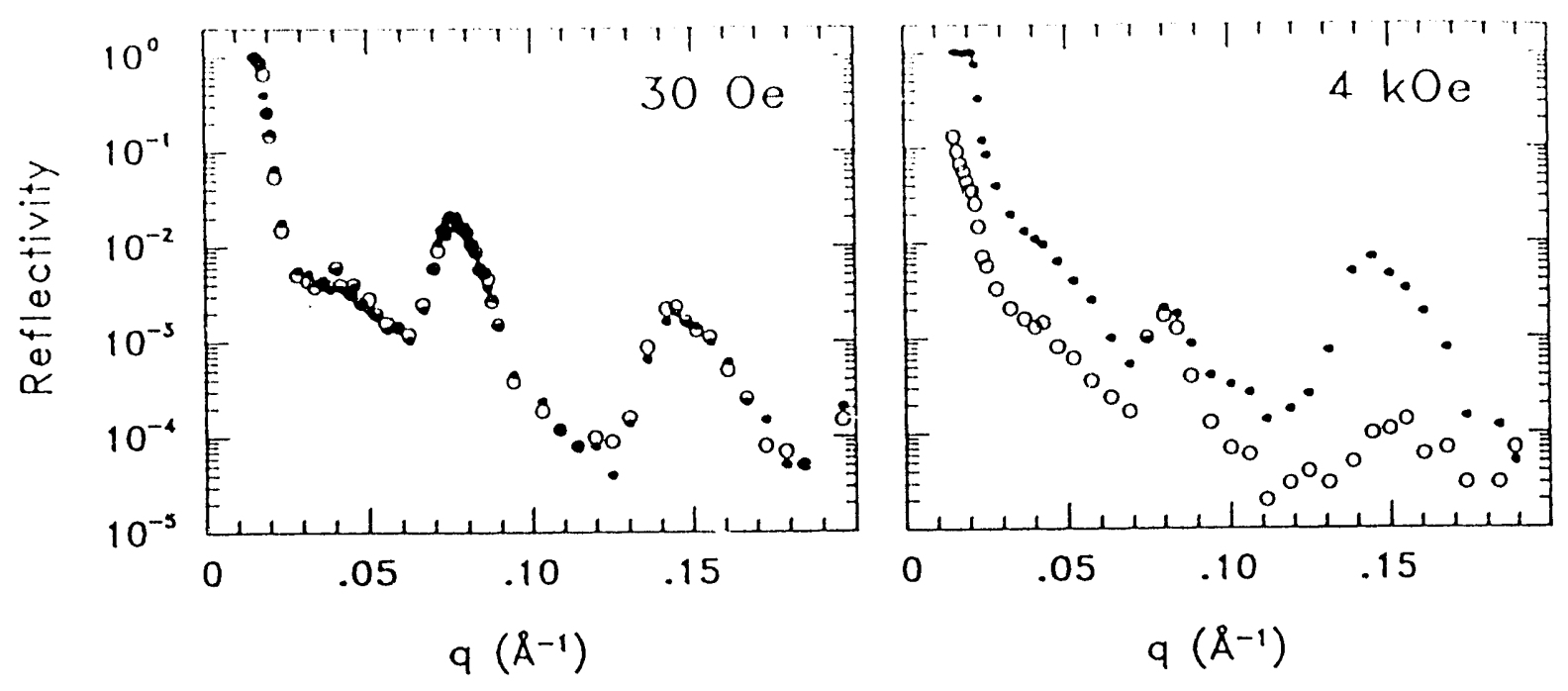

Fig 4 

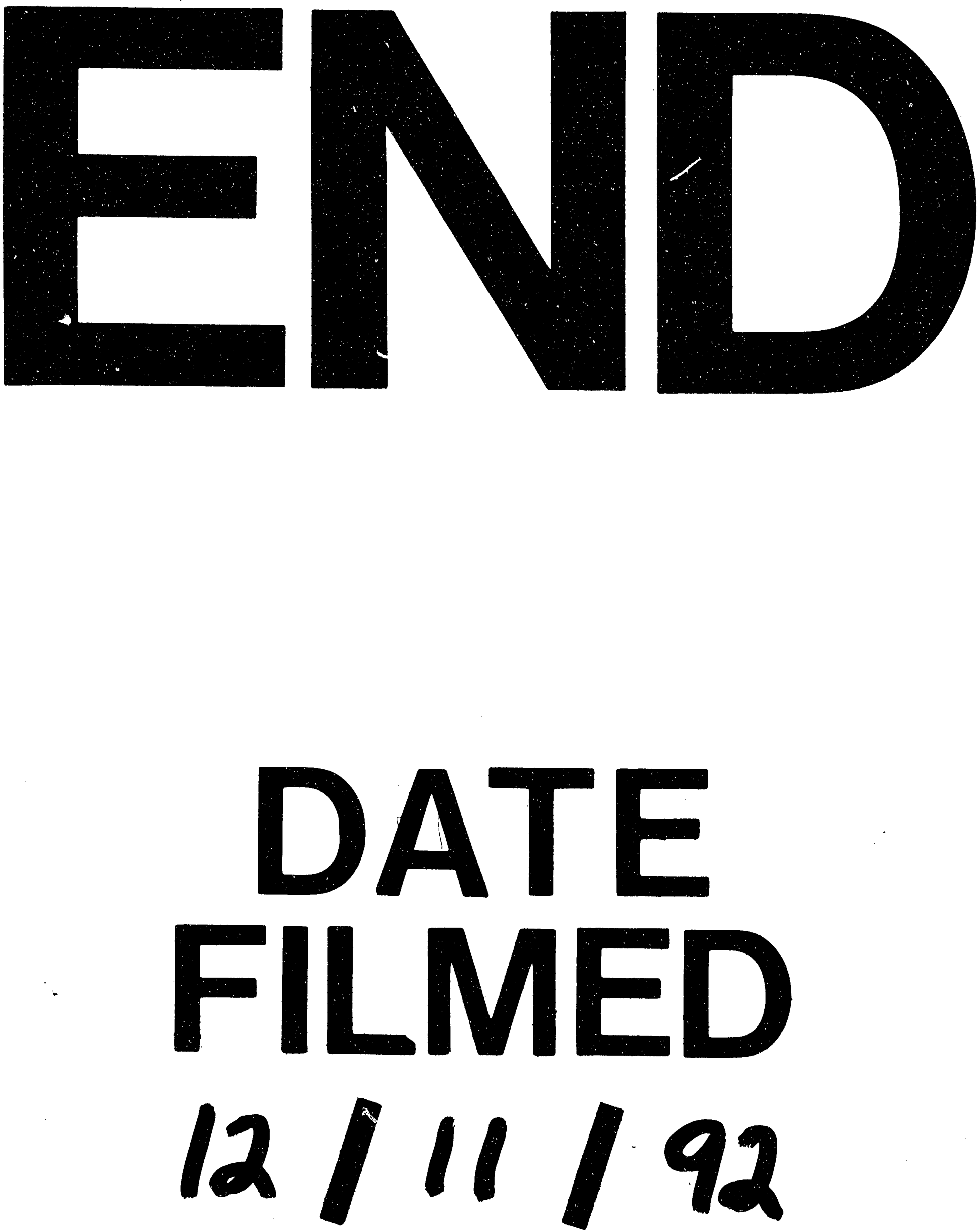

1 
